\title{
Analisis Keakuratan Terjemahan Tindak Tutur Direktif Dalam “Subtitle” Dialog Film The Mask Of Zorro
}

\author{
Lenny Brida ${ }^{1)}$ dan Mawarta Onida Sinaga ${ }^{2)}$ \\ ${ }^{1,2}$ Jurusan Administrasi Niaga, Politeknik Negeri Jakarta \\ E-mail: ${ }^{1}$ lennybrida@gmail.com, ${ }^{2}$ mawarta.onida@bisnis.pnj.ac.id
}

\begin{abstract}
This research is a study of the quality of the translation of directive speech acts in the subtitle of The Mask of Zorro. There are four objectives achieved from this research, namely; 1) identify the types of directive speech acts used in the subtitle of the film dialogue The Mask of Zorro, 2) describe the types of speech acts used at different social strata. 3) describe the techniques used in translating directive speech acts 4). accessing the accuracy of the translation results. The results of the study explained four findings. The first finding shows that the most used directive speech acts category is Requirements (39\%), namely instructing explicitly, ordering, wanting, demanding. the second category is Requestives (35\%) which is used to invite, ask, beg, and invite food. While the speech acts of advices (advices) only (11\%) are encouraging, advising, warning, suggesting.
\end{abstract}

Keywords: Speech, subtitle, directive, requestive, nobility

\begin{abstract}
Abstrak
Penelitian ini merupakan suatu kajian tentang kualitas penerjemahan tindak tutur direktif pada subtitle film The Mask Of Zorro. Ada empat tujuan yang dicapai dari penelitian ini, yaitu; 1) mengidentifikasi jenis-jenis tindak tutur direktif yang digunakan dalam subtitle dialog film The mask of Zorro, 2) mendeskripsikan jenis tindak tutur yang digunakan pada strata sosial yang berbeda. 3) mendeskripsikan teknik-teknik yang digunakan dalam menerjemahkan tindak tutur direktif 4). mengases akurasi hasil terjemahannya. Hasil penelitian menjelaskan empat temuan. Temuan pertama memperlihatkan bahwa kategori tindak tutur direktif yang paling banyak digunakan adalah Requirements (39\%) yaitu menginstruksikan dengan tegas, menyuruh, menghendaki, menuntut. kategori kedua adalah Requestives (35\%) yang digunakan untuk mengajak, meminta, memohon, dan mengundang makan. Sementara tindak tutur nasihat (advices) hanya (11\%) yang bersifat mendorong, menasihati, memperingatkan, menyarankan.
\end{abstract}

Kata kunci: Tindak tutur, subtitle, direktif, requestif, bangsawan

\section{PENDAHULUAN}

\section{Latar Belakang}

Film merupakan teks yang sering hadir dalam kehidupan masyarakat dan merupakan karya estetika yang memiliki bahasa universal, dimana penggemarnya tersebar melintasi aspek-aspek ideologis, agama, suku dan ras. Peluang film menjadi sarana membangun integrasi sosial menjadi sangat terbuka. Dalam konsepsi umum film merupakan media hiburan bagi penikmatnya, tapi pada kenyataannnya film juga memiliki fungsi sosial. Fungsi sosial tersebut dapat dilihat dari dampak positif dan negatif yang ditimbulkan film dalam kehidupan sosial masyarakat.

Pemilihan Film yang dijadikan bahan kajian pada penelitian ini, didasari oleh ketertarikan peneliti terhadap tokoh Zorro, 
sebagai tokoh legenda yang memiliki karakter yang heroik dalam film layar lebar dan serial televisi. The Mask of Zorro adalah film hiburan terbaik yang beredar di dunia, termasuk di Indonesia. Dari banyak review yang diulas oleh beberapa komentator film, kecepatan aksi dan humor yang diperankan oleh Antonio Banderas, dinilai sebagai aktor film yang terbaik sepanjang masa untuk memerankan tokoh Zorro, dibanding tokoh Zorro yang sebelumnya, yang telah pernah diperankan aktor-aktor yang lain.

\section{Rumusan Masalah}

Berdasarkan latar belakang penelitian di atas, maka masalah penelitian yang dapat dirumuskan dalam penelitian ini sebagai berikut:

1. Apa saja jenis-jenis tindak tutur direktif yang terdapat dalam subtitle dialog film The mask of Zorro?

2. Apakah strata sosial seseorang mempengaruhi tindak tutur direktif yang disampaikan?

3. Apa saja teknik-teknik yang dominan digunakan untuk mentransfer tindak tutur direktif dari Bsu ke Bsa?

4. Bagaimana keakuratan hasil penerjemahan "subtitles" film The Mask of Zorro ?

\section{Kajian Pustaka}

\section{Pengertian Subtitling}

Undang-Undang Republik Indonesia Nomor 8 Tahun 1992 pasal 1 ayat (1) tentang perfilman menyebutkan bahwa film adalah karya cipta seni dan budaya yang merupakan media komunikasi massa pandang-dengar yang dibuat berdasarkan asas sinematografi dengan direkam pada pita seluloid, pita video, piringan video dan/atau bahan hasil penemuan teknologi lainnya dalam segala bentuk, jenis dan ukuran melalui proses kimiawi, proses elektronika, atau proses lainnya, dengan atau tanpa suara, yang dapat dipertunjukkan dan/atau ditayangkan dengan sistem mekanik, elektronik dan/atau lainnya.Dengan perkembangan film yang begitu pesat, banyak film beredar dimasyarakat, baik film lokal maupun film mancanegara.

Subtitling adalah proses penerjemahan teks film. Shuttleworth dan Cowie (1997:161) menyatakan bahwa subtitling is the process of providing synchronized captions for film and television dialogue (and more recently for live opera). O’Connel (2007:169) menjelaskan bahwa subtitling is defined as supplementing the original voice soundtrack by adding written text. Dari pendapat di atas dapat disimpulkan bahwa subtitling merupakan pengalihan pesan dari bahasa sumber (bahasa lisan) kedalam bahasa sasaran dalam bentuk tulis/teksyang ditampilkan bersamaan pada saat dialog diucapkan. Pembuatan subtitle film pada dasarnya bukanlah pekerjaan yang mudah dilakukan karena dibatasi oleh dua faktor yaitu media dan waktu. Dari faktor media artinya bahwa teks terjemahan akan ditampilkan dilayar dengan ruang yang jauh lebih sempit daripada buku atau novel.

\section{Kesulitan dalam Subtitling}

Hatim dan Mason

(1997:78)

menyatakan empat kendala utama dalam subtitling yang mengakibatkan kesulitankesulitan tertentu oleh penerjemah, yaitu:

1. Pergeseran mode dari lisan ke dalam tulisan. Hal ini akan memungkinkan ciri-ciri tutur tertentu, seperti dialek tidak baku, intonasi alih kode dan turn taking tidak akan terwakilkan dalam bentuk tertulis bahasa sasaran.

2. Terikat oleh media atau saluran pengalihan pesan tersebut yang dilakukan meliputi batasan waktu dan tempat terkait dengan jumlah baris dan karakter pertayang.

3. Terjadinya reduksi data teks sumber. Oleh karena itu, penerjemah harus bekerja keras untuk berusaha mengalihkan teks sumber ke dalam bahasa sasaran yang lebih ringkas tanpa mengurangi makna dari pesan yang akan disampaikan. 
4. Kesesuaian dengan gambar visual. Karena gambar visual dan audio merupakan hal yang tidak terpisahkan dari film, maka koherensi antara teks dan gambar bergerak harus sesuai.

\section{Pengertian Pragmatik}

Istilah pragmatik diperkenalkan oleh seorang filosof yang bernama Charless Morris tahun 1938. Ia menjelaskan dalam (Djatmika, 2016:12) bahwa semiotika memiliki tiga bidang kajian, yaitu sintaksis (syntax), semantik (semantics), dan pragmatik (pragmatics). Sintaksis merupakan kajian linguistik yang mengkaji hubungan formal antar tanda. Semantik adalah kajian linguistik tentang hubungan tanda dengan orang yang menginterpretasikan tanda tersebut.

\section{Tindak tutur (Speech act)}

Yule ( 1996: 47) mengatakan bahwa speech act is actions performed via utterances. Ketika seseorang berbicara dia tidak hanya sedang mempertukarkan informasi tetapi juga melakukan sebuah tindakan. Menurut Yule, kata yang disampaikan oleh si penutur tidak hanya mengandung makna harafiah tetapi juga mengandung suatu tindakan. Misalnya dalam kalimat aku lapar. Kalimat ini tidak hanya sebagai pernyataan (statement) yang menyatakan penutur dalam keadaan lapar tetapi juga si penutur mungkin bermaksud untuk meminta sesuatu untuk dimakan. Peran konteks kalimat harus diperhatikan karena suatu ujaran/tuturan penutur dapat mengandung maksud yang berbeda-beda tergantung pada konteks yang menyertainya.

\section{Tindak Tutur Direktif ( Speech act of Directives)}

Menurut Rohmadi, teori tindak tutur pertama kali dikemukakan oleh Austin (1956), seorang guru besar di Universitas Harvard. Teori yang berwujud hasil kuliah itu kemudian dibukukan oleh J.O.Urmson (1965) dengan judul How to do Things with words?. Akan tetapi teori itu baru berkembang secara mantap setelah Searle (1969) menerbitkan buku yang berjudul Speech Acts : An Essay in the Philosophy of language menurut Searle dalam semua komunikasi linguistik terdapat tindak tutur. Ia berpendapat bahwa komunikasi bukan sekadar lambang, kata atau kalimat, tetapi akan lebih tepat apabila disebut produk atau hasil dari lambang, kata atau kalimat yang berwujud perilaku tindak tu $\neg$ tur (fire performance of speech acts).

Tindak tutur merupakan analisis pragmatik, yaitu cabang ilmu bahasa yang mengkaji bahasa dari aspek pemakaian aktualnya. Leech[2]menyatakan bahwa pragmatik mempelajari maksud ujaran (yaitu untuk apa ujaran itu dilakukan); menanyakan apa yang seseorang maksudkan dengan suatu tindak tutur; dan mengaitkan makna dengan siapa berbicara kepada siapa, di mana, bilamana, bagaimana. Tindak tutur merupakan entitas yang bersifat sentral di dalam pragmatik dan juga merupakan dasar bagi analisis topik-topik lain di bidang ini seperti praanggapan, perikutan, implikatur percakapan, prinsip kerjasama dan prinsip kesantunan.

Bach dan Harnish (1979) dalam Ibrahim[8] menyatakan bahwa direktif mengekspresikan sikap penutur terhadap tindakan yang akan dilakukan oleh mitra tutur sehingga tindakan ini dapat berbentuk konstatif, namun direktif juga bisa mengekspresikan maksud penutur (keinginan, harapan) sehingga ujaran aatau sikap yang diekspresikan dijadikan sebagai alasan untuk bertindak oleh mitra tutur. Selanjutnya Bach dan Harnish dalam Ibrahim[9]mengkategorikan direktif ke dalam enam kategori utama yaitu: 1) Requestives (meminta, mengemis, memohon, menekan, mengundang, mendoa, mengajak, mendorong), 2) Questions (bertanya, menyelidik, menginterogasi), 3) Requirements (memerintah, menghendaki, mengkomando, menuntut, mendikte, mengarahkan, menginstrusikan, 
mengatur, mensyaratkan), 4) Prohibitives (melarang, membatasi), 5) Permissives (menyetujui, membolehkan, memberi wewenang, menganugerahi, mengabulkan, membiarkan, mengijinkan, melepaskan, memaafkan, memperkenankan), dan 6) Advisories (menasehatkan, memperingatkan, mengkonseling, mengusulkan, menyarankan, mendorong).

\section{Tindak tutur langsung dan tak langsung}

Secara formal berdasarkan modusnya, kalimat dibedakan menjadi kalimat berita (deklaratif), kalimat tanya (interrogative) dan kalimat perintah (imperative). Secara konvensional kalimat berita (deklaratif) digunakan untuk memberitahukan sesuatu (informasi); kalimat tanya untuk menanyakan sesuatu, dan kalimat perintah untuk menyatakan perintah, ajakan, permintaaan atau permohonan. Apabila kalimat berita difungsikan secara konvensional untuk mengadakan sesuatu, kalimat tanya untuk bertanya dan kalimat perintah untuk menyuruh, mengajak memohon dan sebagainya, maka akan terbentuk tindak tutur langsung (direct speech). Sebagai contoh : Yuli merawat ayahnya. Siapa orang itu? Ambilkan buku saya! Ketiga kalimat tersebut merupakan tindak tutur langsung berupa kalimat berita, tanya, dan perintah. Tindak tutur tak langsung (indirect speech act) ialah tindak tutur untuk memerintah seseorang melakukan sesuatu secara tidak langsung. Tindakan ini dilakukan dengan memanfaatkan kalimat berita atau kalimat tanya agar orang yang diperintah tidak merasa dirinya diperintah. Misalnya seorang ibu menyuruh anaknya mengambil sapu, diungkapkan dengan Upik, sapunya dimana?” Kalimat tersebut selain untuk bertanya sekaligus memerintah anaknya untuk mengambilkan sapu.

\section{Tindak tutur literal dan tindak tutur tak literal}

Tindak tutur literal (literal speech act) adalah tindak tutur yang dimaksudnya sama dengan makna kata-kata yang menyusunnya. Sedangkan tindak tutur tidak literal (nonliteral speech act) adalah tindak tutur yang dimaksudnya tidak sama dengan atau berlawanan dengan kata-kata yang menyusunnya. Sebagai contoh dapat dilihat kalimat berikut.

a. Penyanyi itu suaranya bagus.

b. Suaramu bagus (tapi kamu tidak usah menyanyi)

Kalimat (a) jika diutarakan dengan maksud untuk memuji atau mengagumi suara penyanyi yang dibicarakan, maka kalimat itu merupakan tindak tutur literal, sedangkan kalimat (b) penutur bermaksud mengatakan bahwa suara lawan tuturnya jelek, yaitu dengan mengatakan "Tak usah menyanyi”. Tindak tutur pada kalimat (b) merupakan tindak tutur tak literal.

Apabila tindak tutur langsung dan tak langsung diinteraksikan dengan tindak tutur literal dan tak literal, maka akan tercipta tindak tutur sebagai berikut :

1. Tindak tutur langsung literal (direct literal speech act), ialah tindak tutur yang diutarakan dengan modus tuturan dan makna yang sama dengan maksud pengutaraannya. Maksud memerintah disampaikan dengan kalimat perintah, memberitakan dengan kalimat berita, dan menanyakan sesuatu dengan kalimat tanya. Misalnya : Ambilkan buku itu! Kusuma gadis yang cantik”, Berapa saudaramu, Mad?

2. Tindak tutur tidak langsung literal (indirect literal speech act) adalah tindak tutur yang diungkapkan dengan modus kalimat yang tidak sesuai dengan maksud pengutaraannya, tetapi makna katakata yang menyusunnya sesuai dengan apa yang dimaksudkan oleh penutur. Misalnya : "Lantainya kotor”. Kalimat itu jika diucapkan seorang ayah kepada anaknya bukan 
saja menginformasikan, tetapi sekaligus menyuruh untuk membersihkannya.

3. Tindak tutur langsung tidak literal (direct non literal speech) adalah tindak tutur yang diutarakan dengan modus kalimat yang sesuai dengan maksud dan tuturan, tetapi kata-kata yang menyusunnya tidak memiliki makna yang sama dengan maksud penuturnya. Misalnya : "Sepedamu bagus, kok”. Penuturnya sebenarnya ingin mengatakan bahwa sepeda lawan tuturnya jelek.

4. Tindak tutur tidak langsung tidak literal (indirect non literal speech act) adalah tindak tutur yang diutarakan dengan modus kalimat yang tidak sesuai dengan maksud yang ingin diutarakan. Untuk menyuruh seorang pembantu menyapu lantai kotor, seorang majikan dapat saja mengutarakannya dengan kalimat “Lantainya bersih sekali, Mbok”.

\section{Teknik Penerjemahan}

Teknik penerjemahan adalah implementasi operasional dari metode penerjemahan yang sudah ditetapkan oleh si penerjemah. Sebagaimana yang diungkapkan oleh Molina \& Albir (2002: 509) bahwa teknik penerjemahan adalah cara yang diterapkan oleh penerjemah ketika mencari padanan teks yang diterjemahkan pada saat penerjemahan berlangsung. Selanjutnya, Nababan (2010 : 6) juga menjelaskan bahwa padanan teks yang dimaksud dapat berlaku pada semua satuan lingual, yaitu kata, frasa, klausa maupun kalimat. Setiap pakar memiliki istilah tersendiri dalam menentukan suatu teknik/cara penerjemahan, sehingga cenderung terjadi tumpang tindih antara teknik pakar yang satu dengan yang lainnya. Teknik yang dimaksud sama tetapi memiliki terminologi yang berbeda. Dalam hal keberagaman pemikiran para pakar, di satu sisi memberi kontribusi positif, akan tetapi di sisi lain dapat menimbulkan kesulitan dalam menentukan terminologi teknik mana yang digunakan atau dipilih para penerjemah.

Untuk mempermudah kajian penelitian ini, peneliti mengadopsi 18 jenis teknik penerjemahan yang diperkenalkan Molina \& Albir (2002 : 509 ), yang telah disimpulkannya melalui penelitian mendalam dengan menelaah berbagai teknik penerjemahan yang telah ada dari pakar penerjemahan sebelumnya. Jenis teknik penerjemahan ini dapat dilihat pada matriks berikut ini: Teknik Adaptasi (adaptation), Teknik Amplifikasi, Teknik Peminjaman (borrowing), Teknik Harfiah, Teknik Calque, Teknik Kompensasi (compensation), Teknik Deskripsi (description), Teknik Kreasi diskursif (discursive creation), Teknik Kesepadanan Lazim (established equivalent), Teknik Generalisasi (generalization), Teknik Amplifikasi linguistik (linguistic amplification), Teknik Kompresi lingu-istik (ling. compression), Teknik Modulasi (modulation), Teknik Partikularisasi (particularization), Teknik Reduksi (reduction), Teknik Substitusi (substitution), Teknik Transposisi (transposition), Teknik Variasi (Variation).

Teknik-teknik penerjemahan di atas cukup bervariasi, selain didasari ideologi dan metode yang secara implisit mewarnai proses penerjemahan, tetapi juga perlu disadari bahwa muara dari karya terjemahan adalah keakuratan, keterbacaan dan keberterimaan pembaca sasaran yang dituju.

Jika dicermati teknik-teknik di atas, pada umumnya adalah merupakan upaya membantu pembaca dalam memahami hasil terjemahan. Meski banyak yang mengkritisi bahwa peminjaman kata atau penggunaan "slang" merupakan penyimpangan dalam terjemahan, tetapi tidak dapat dipungkiri bahwa kenyataannya tidak ada bahasa yang benar-benar original, seperti yang 
diungkapkan oleh A Nida, Eugine (2005 : 1) di bawah ini :

"There are no pure languages. In fact, more than half of the vocabulary of English comes from languages all over the world, eg tomato from Spanish, thug from Hindi,

\section{HASIL DAN PEMBAHASAN}

Pendeskripsian hasil dan pembahasan tindak tutur direktif dan teknik-teknik penerjemahan dalam merekonstruksi makna dari setiap kategori tindak tutur merupakan jawaban terhadap pertanyaan penelitian yang dirumuskan pada bab I. Hasil penelitian dan pembahasan difokuskan kepada empat permasalahan, yaitu 1) Mengidentifikasi jenis-jenis tindak tutur direktif apa saja yang terdapat dalam subtitle dialog film The mask of Zorro. 2). Mengidentifikasi strata sosial seseorang yang mempengaruhi kategori tindak tutur direktif yang disampaikan. 3) Mengidentifikasi teknik-teknik penerjemahan yang digunakan penerjemah 4) Mengkaji dampak teknikteknik penerjemahan terhadap keakuratan.

\section{Jenis Tindak Tutur Direktif dalam Film The Mask of Zorro}

Sesuai dengan permasalahan dan tujuan penelitian ini, analisis terhadap jenis-jenis tindak tutur direktif yang terdapat dalam film The Mask of Zorro, merujuk kepada teori Batch \& Harnish (1979). Jenis tindak tutur direktif yang peneliti temukan dalam film The Mask of Zorro meliputi tindak tutur direktif Requestives, Requirements, questions, prohibitives dan, Advisories. Hasil analisis temuan penelitian ini dipaparkan sebagai berikut:

Tabel 1. Kategori Tindak Tutur dan frequensinya dalam Film The Mask of Zorro

\begin{tabular}{llll}
\hline NO & $\begin{array}{l}\text { Kategori Tindak } \\
\text { Tutur }\end{array}$ & Frequensi & $\begin{array}{l}\text { Prosenta } \\
\text { se }\end{array}$ \\
\hline 1 & Requirements & 65 & $39 \%$ \\
2 & Requestives & 58 & $35 \%$ \\
3 & Advisories & 18 & $11 \%$ \\
4 & Questions & 15 & $9 \%$ \\
5 & Prohibitives & 10 & $6 \%$ \\
\hline
\end{tabular}

\section{Teknik Penerjemahan Subtitle Film} The Mask of Zorro

Dari hasil analisis yang dilakukan peneliti terdapat 183 teknik penerjemahan yang dilakukan. Mengapa jumlah teknik lebih banyak dari jumlah data karena ada tindak tutur yang diterjemahkan dengan beberapa kombinasi teknik penerjemahan.

Tabel 2.Kategori Teknik Penerjemahan Subtitle Film tha Mask of Zorro

\begin{tabular}{clll}
\hline \multirow{2}{*}{ NO } & JENIS TEKNIK PENERJEMAHAN & \multicolumn{2}{c}{ TOTAL } \\
\cline { 3 - 4 } & & 66 & Frekuensi \\
\hline 1 & Teknik Harfiah & 50 & $36 \%$ \\
2 & Teknik Transposisi & 32 & $27,4 \%$ \\
3 & Teknik Reduksi & 9 & $17,6 \%$ \\
4 & Teknik Adaptasi & 9 & $5 \%$ \\
5 & Teknik Amplifikasi Linguistik & 8 & $5 \%$ \\
6 & Teknik Borrowing & 7 & $4,3 \%$ \\
7 & Teknik Kesepadanan Lazim & 2 & $3,7 \%$ \\
8 & Teknik Kreasi Diskursif & 183 & $1 \%$ \\
& & & $100 \%$ \\
\hline
\end{tabular}

\section{Asesmen Keakuratan Subtitle}

Dalam pengukuran keakuratan instrument , peneliti mengadopsi parameter yang digunakan oleh Nababan (2012) yaitu menggunakan rating scale 3- 2-1, 3 adalah skor tertinggi , 2 adalah skor tengah (medium) dan 1 adalah skor terendah. Dalam mempertimbangkan kriteria dan parameter yang dirujuk. Hasilnya adalah sebagai berikut. 
Tabel 3. Rentang Skor Asesmen Kualitas

Terjemahan

\begin{tabular}{lll}
\hline NO & Kategori & Range of Score \\
\hline 1 & Akurat & $2,6-3,0$ \\
2 & Medium & $2,0-2,5$ \\
3 & Tidak Akurat & $0,0-1,9$ \\
\hline \multicolumn{2}{c}{ Sumber : Nababan 2012. }
\end{tabular}

\section{Hasil Assessmen}

Berdasarkan hasil asesmen para rater dan FGD dengan beberapa informan, hasil skornya adalah sebagai berikut :

Tabel 4. The result of the accuracy assessment of the subtitle.

\begin{tabular}{llll}
\hline NO & $\begin{array}{l}\text { Kategori } \\
\text { Kualitas }\end{array}$ & $\begin{array}{l}\text { Total skor rata- } \\
\text { rata } \\
\text { score }\end{array}$ \\
\hline 1 & Akurasi & $\begin{array}{l}104 \times 3+45 \times 2+2,21 \\
3 \times 1: 183\end{array}$ \\
\hline
\end{tabular}

Catatan : Total skor rata-rata dibagi total data.

Hasil pengukuran keakuratan subtitle ditemukan skor keakuratan sebesar 2,21. Jika dirujuk kategori table yang diadopsi dari Nababan (2012) maka dapat disimpulkan bahwa keakuratan Subtitle masuk kategori medium . Dari hasil analisis ini dapat diinterpretasi bahwa rendahnya keakuratan adalah karena kesalahan memilih teknik penerjemahan yang agak rigid karena banyak menggunakan teknik harfiah.

\section{KESIMPULAN DAN SARAN Kesimpulan}

Berdasarkan hasil analisis dan pembahasan pada bab-bab sebelumnya, maka dapat ditarik kesimpulan sebagai berikut:

1. Dalam Film the Mask of Zorro, Kategori tindak tutur Direktif yang paling banyak digunakan adalah Requirements (39\%) yaitu memerintah (strong and polite), menyuruh, menghendaki, menuntut dll. Penggunaan tindak tutur kedua adalah Requestives (35\%) yang pada umumnya digunakan untuk mengajak, meminta, memohon, mengundang makan, dll. Urutan penggunaan advices (nasihat) hanya (11\%) yang pada umumnya mendorong, menasihati, memperingatkan, menyarankan, dll. Tindak tutur direktif juga digunakan dalam bentuk questions oleh para Don dan kaum bangsawan. Instruksi dan perintah disampaikan dalam kalimat Tanya.

2. Data di atas ini menggambarkan bahwa teknik yang dominan dalam merekonstruksi tindak tutur direktif adalah teknik harfiah. Hal ini juga dipengaruhi oleh tempat dan waktu tayang yang terbatas. Dari data di atas ditemukan bahwa teknik harfiah adalah teknik yang paling sering digunakan (66 kasus), kemudian keterbatasan tempat tayang subtitle mengakibatkan banyak terjadi penyesuaian pada terjemahan sehingga terjadi pergeseran. (50 kasus). Otomatis Film ini juga menggunakan teknik reduksi untuk frekuaensi yang cukup besar (32 kasus) karena penayangan subtitle dibatasi oleh waktu dan tempat.

3. Ada kecenderungan penggunaan tindak tutur dalam bentuk question bagi para bangsawan Spanyol dan cendering lebih sopan.

4. Hasil pengukuran keakuratan subtitle ditemukan skor keakuratan sebesar 2,21. Jika dirujuk kategori table yang diadopsi dari Nababan (2012) maka dapat disimpulkan bahwa keakuratan Subtitle masuk kategori medium . Dari hasil analisis ini dapat diinterpretasi bahwa rendahnya keakuratan adalah karena kesalahan memilih teknik penerjemahan yang agak rigid karena banyak menggunakan teknik harfiah.

\section{Saran}

Berdasarkan hasil analisis data dan simpulan di atas, maka peneliti menyarankan beberapa hal sebagai berikut :

1. Kepada penerjemah film the Mask Of Zorro agar tidak terlalu banyak menggunakan teknik harfiah. Meski subtitle dibatasi ruang dan waktu 
tetapi tetap harus dijaga keakuratannya agar pewsan budaya yang disampaikan dapat disampaikan oleh subtitler.

2. Kepada para pakar asesmen kualitas terjemahan, para peneliti dan akdemisi, para praktisi penerjemahan yang tertarik dalam mengukur kualitas karya terjemahan, disarankan untuk menyusun standar-standar kualitas karya terjemahan yang disepakati dan dikonvensikan bersama oleh komunitas penerjemah baik dari unsur praktisi, akademisi maupun stake holder lainnya, agar terdapat kesamaan pandangan terhadap parameter, instrumen dan prosedur asesmen yang ditetapkan secara baku.

\section{DAFTAR PUSTAKA}

Austin, J.L. 1962. How to Do Things with Words. London: Oxford University Press.

Fawcett, Peter. 1997. Translation Theory Explained. Britania Raya: St. Jerome Publishing.

Djatmika. 2016. Mengenal Pragmatik Yuk. Jogyakarta : Pustaka Pelajar

Hermaji, Bowo. 2015. Teori Pragmatik. Semarang: Tunas Puitik

Ibrahim, Abd. Syukur. 1993. Kajian Tindak Tutur. Surabaya: Usaha Nasional.

Levinson, Stephen.1983. Pragmatics. London: Cambridge University Press.

Leech, Geoffrey. 1993. Prinsip-prinsip Pragmatik. Jakarta: UI Press.

Mihardja, Achdiat K. 2006. Atheis. Jakarta: Balai Pustaka

Nababan, M.R. (2010). Pengembangan Model Penilaian Kualitas Terjemahan.

Laporan akhir penelitian Hibah Kompetensi Bacth III Tahun II (2010).Jurusan Sastra Inggris FSSR UNS 2010.
Nababan, Nuraeni \& Sumardiono. 2012. Pengembangan Model Kualitas Terjemahan. Kajian Linguistik dan Satra. Vol.24, No.1 